\title{
Sodium tanshinone IIA sulfonate suppresses heat stress- induced endothelial cell apoptosis by promoting NO production through upregulating the PI3K/AKT/eNOS pathway
}

\author{
QING CHENG, YAN ZHAO and JIANGUO LI
}

\author{
Department of Emergency, Zhongnan Hospital of Wuhan University, Wuhan, Hubei 430071, P.R. China
}

Received June 13, 2016; Accepted April 10, 2017

DOI: $10.3892 / \mathrm{mmr} .2017 .6760$

\begin{abstract}
Heat shock is a life-threatening disease involving systematic inflammation that is closely related to endothelial injury and can lead to multiple organ dysfunction syndrome. Sodium tanshinone IIA sulfonate (STS) has various functions in the vascular endothelium. In the present study, STS is presented to suppress heat stress-induced apoptosis of human umbilical vein endothelial cells (HUVECs) and high ambient temperature-induced systematic inflammation in Sprague Dawley rats. In addition, the STS apoptosis-suppression mechanism was explored. The results presented in the present study demonstrated that the PI3K/AKT pathway was stimulated by STS treatment and that eNOS phosphorylation at Ser-1177 was also upregulated, resulting in increased nitric oxide production in HUVECs under heat stress. Using specific inhibitors, the authors confirmed that STS-induced endothelial nitric oxide synthase (eNOS) phosphorylation at Ser-1177 was activated by protein kinase B phosphorylation at Ser-473, involving activation of phosphatidylinositol-3 kinase (PI3K). The results suggested that STS suppresses heat stress-induced apoptosis of HUVECs via the PI3K/AKT/eNOS pathway and may be used in heat shock treatment as a vascular endothelial protection mechanism.
\end{abstract}

\section{Introduction}

Exposure to high ambient temperatures can result in heat stroke, a clinical condition characterized by a rapid rise core temperature above $40^{\circ} \mathrm{C}$, which is associated with central nervous system alterations such as delirium, convulsions or coma (1). The pathogenesis of tissue injury and cell death due to heat stroke is not well understood, which may explain the

Correspondence to: Professor Yan Zhao or Professor Jianguo Li, Department of Emergency, Zhongnan Hospital of Wuhan University, 169 Donghu Road, Wuhan, Hubei 430071, P.R. China

E-mail: zhaoyanznjzk@126.com

E-mail: znjzkjianguoli@163.com

Key words: heat stroke, endothelial injury, sodium tanshinone IIA sulfonate, apoptosis, endothelial nitric oxide synthase high morbidity and mortality associated with heat stroke, as no specific mechanisms can be targeted for treatment $(2,3)$. Previous studies suggest that systemic inflammatory response syndrome (SIRS) is directly related to the severity of the heat insult, which ensues during heat stroke $(4,5)$. Among the most prominent features of heat stroke-related SIRS, endothelial injury contributes significantly to its outcome $(6,7)$.

The activation of coagulation disorders with the concurrent downregulation of anticoagulant systems and fibrinolysis are associated with key symptoms, such as hypovolemia and hypotension. Impaired endothelium promotes platelet adhesion via the secretion of von Willebrand factor and secretes an extracellular matrix that supports platelet adhesion following vascular injury (8). Vascular injury promotes inflammation, cell adherence to vascular endothelium and invasion of organs that receive blood supply from the injured vasculature. Vascular endothelial injury-induced adhesion, invasion of inflammatory cells and coagulant disorders contribute to disseminated intravascular coagulation, a syndrome characterized by widespread intravascular thrombosis that can compromise adequate blood supply to various organs (9). This serious syndrome has been implicated in multiple organ dysfunction syndromes (MODSs) and leads a high mortality of heatstroke $(10,11)$. Therefore, prevention of endothelial cell injury is a potential strategy to reduce the high rate of heat shock-induced morality.

Previous studies have suggested that endothelial cells are an early target of heat stress injury and that damaged endothelial cells are prominent features of severe heat stroke and can be induced to undergo apoptosis during the acute response phase to heat stress $(12,13)$. NO and equivalent amounts of citrulline are synthesized from guanidino nitrogen of L-arginine by nitric oxide synthases (NOS) identified in endothelial cells and neurons and can be activated in most cell types. NO can also act as an anti-apoptotic agent (14). Relatively low concentrations of NO appear to favor cell proliferation and anti-apoptosis responses, which activate pathways of cell cycle arrest, mitochondrial respiration and apoptosis (15). Endothelial NO production leads to vasodilation and increases tissue perfusion, which leads to inflammatory cell migration from the vascular to the supported tissue. This results in an inflammation response in the target tissue and MODS. Therefore, elevation of NO production in vascular endothelial cells suppresses inflammation and multi-organ injury and 
represents a potential pathway to treat systematic inflammation response-related diseases including heat stroke.

Sodium tanshinone IIA sulfonate (STS) is a derivative of tanshinone II A, which is isolated from the root of Salvia miltiorrhiza. Injection of STS is used widely and successfully in clinics in China for treating cardiovascular diseases as a vascular-protecting drug (16). In addition, it is used as a vascular remodeling inducer and inflammation controller (17). Based on the known functions and possible mechanisms of STS, the authors tested STS for its ability to control inflammatory responses due to heat shock. The outcomes of STS treatment were good, inline with a previous study of the authors, but the exact mechanism of its therapeutic effect is poorly understood. Therefore, the present study was conducted to explore how STS suppresses inflammation, which is associated with vascular endothelial protection.

\section{Materials and methods}

HUVEC culture. HUVECs were obtained from a Chinese Center for Type Culture Collection (Wuhan, China). Cells were cultured in Dulbecco's modified Eagle medium (DMEM, Invitrogen, Thermo Fisher Scientific, Inc., Waltham, MA, USA) with low glucose containing $10 \%$ fetal bovine serum (FBS, Hyclone; GE Healthcare Life Sciences, Chalfont, $\mathrm{UK}$ ) and $2 \mathrm{mM}$ L-glutamine (Sigma-Aldrich; Merck KGaA; $\mathrm{G} 3126)$ and were grown on tissue culture dishes at $37^{\circ} \mathrm{C}$ in $5 \% \mathrm{CO}_{2}$ at $100 \%$ humidity. Non-adherent cells were removed by washing with phosphate buffered saline, and the culture liquid was refreshed every $2 \mathrm{~d}$. Cells were subcultured at $80 \%$ confluence. Primary cultures of HUVECs between passages 5 and 10 were used in all experiments.

High temperature exposure. HUVECs were grown to $~ 80 \%$ confluence in $100 \mathrm{~mm}$ dishes in DMEM supplemented with $10 \%$ FBS (v/v) prior to the start of the experiments. For the high temperature exposure, the cell cultures were placed in an incubator chamber flushed with a gas mixture of $5 \% \mathrm{CO}_{2}$ at $42^{\circ} \mathrm{C}$ for various time periods and treatments, as needed.

Drug and pharmacological interventions. The drug STS was used at a final concentration of $2 \mu \mathrm{g} / \mathrm{ml}$. The following pharmacological inhibitors were used: NOS inhibitor $\mathrm{N}^{\mathrm{G}}$ monomethyl-L-arginine (L-NMMA; $250 \mathrm{mM}$; EMD Millipore, Billerica, MA, USA), AKT inhibitor MK-2206 (5 $\mu \mathrm{M}$; Selleck Chemicals, Houston, TX, USA), and PI3K inhibitor wortmannin (500 nM; Sigma-Aldrich; Merck KGaA). Each intervention drug was dissolved in $10 \%$ FBS in DMEM and was added to the cell cultures $30 \mathrm{~min}$ prior to initiating the high temperature exposure.

Western blotting. HUVECs were lysed in $300 \mu \mathrm{l}$ lysis buffer (50 mM Tris, $\mathrm{pH} \mathrm{7.4,} \mathrm{1 \%} \mathrm{Triton} \mathrm{X-100,} \mathrm{0.25 \%} \mathrm{Na} \mathrm{deoxycho-}$ late, $150 \mathrm{mM} \mathrm{NaCl}, 1 \mathrm{mM}$ EGTA, $1 \mathrm{mM}$ PMSF, $1 \mathrm{mM} \mathrm{NaF}$, $10 \mathrm{mg} / \mathrm{ml}$ aprotinin, $1 \mathrm{mg} / \mathrm{ml}$ leupeptin and $1 \mathrm{mM}$ orthovanadate). The total protein concentration was determined using a BCA protein assay kit (Pierce; Thermo Fisher Scientific, Inc.). A measure of $10 \mathrm{mg} /$ well proteins was subjected to SDS-PAGE on $10 \%$ polyacrylamide gels and transferred to nitrocellulose membranes. The membranes were blocked with $5 \%$ bovine serum albumin at $4^{\circ} \mathrm{C}$ overnight prior to incubation with antibodies. Immunoblotting was performed with rabbit anti-eNOS (1:1,000; catalog no. 32027S; Cell Signaling Technology, Inc., Danvers, MA, USA), rabbit anti-phospho-eNOS (Ser1177, 1:1,000, catalog no. 9570S; Cell Signaling Technology, Inc.), rabbit anti-Akt (1:1,000, catalog no. 9272; Cell Signaling Technology, Inc.) or rabbit anti-phospho-AKT antibody (Ser473, 1:1,000 dilution, catalog no. sc-7985-R; Santa Cruz Biotechnology, Inc., Dallas, TX, USA) overnight at $4^{\circ} \mathrm{C}$. The membrane was then washed and incubated with horseradish peroxidase-conjugated goat anti-rabbit IgG (1:2,500; catalog no. 554021; BD Biosciences, Franklin Lakes, NJ, USA) at room temperature for $1.5 \mathrm{~h}$. The membranes were developed using the Western Blot Chemiluminescence Detection reagent (PerkinElmer, Inc., Waltham, MA, USA).

Cell counting kit-8 (CCK-8) assay. The viability of stimulated HUVEC cells was determined using a CCK-8 assay (Beyotime Institute of Biotechnology, Haimen, China) following the manufacturer's protocol. Optical density (OD) at a wavelength of $450 \mathrm{~nm}$ (formation of formazan) was measured using a Thermo Scientific microplate reader and SkanIt ${ }^{\mathrm{TM}}$ software version 3.1 (Thermo Fisher Scientific, USA).

Flow cytometry. For detection of apoptosis, stimulated HUVEC cells $\left(1 \times 10^{6}\right)$ were stained with Annexin $\mathrm{V}$-conjugated to fluorescein isothiocyanate (FITC) and propidium iodide (PI) by using a FITC Annexin V/Dead Cell Apoptosis kit (BioVision, Inc., Milpitas, CA, USA) following the manufacturer's protocol. Briefly, cells were suspended in $500 \mu \mathrm{l}$ Annexin $\mathrm{V}$ binding buffer and incubated with $5 \mu \mathrm{l}$ Annexin $\mathrm{V}$ and $5 \mu \mathrm{l}$ PI for $5 \mathrm{~min}$ at room temperature in the dark. Percentages of cells undergoing apoptosis were determined by dual-color analysis. Immediately after staining, the cells were analyzed on a flow cytometer using $488 \mathrm{~nm}$ excitation and a $525 \mathrm{~nm}$ band pass filter for FITC and a $620 \mathrm{~nm}$ filter for PI detection. At least 20,000 cells were acquired using a Beckman Coulter flow cytometer and Beckman Summit version 6.1.0 software (Beckman Coulter, Inc., Brea, CA, USA).

Immunoprecipitation of eNOS and blotting with phospho-eNOS. HUVECs were washed and incubated in lysis buffer containing $20 \mathrm{mM}$ Tris- $\mathrm{HCl}$ (pH=7.4), $150 \mathrm{mM}$ $\mathrm{NaCl}, 1 \mathrm{mM}$ EGTA, $1 \mathrm{mM}$ EDTA, $1 \%$ Triton X-100, $1 \mathrm{mM}$ PMSF, $1 \mathrm{mM} \mathrm{NaF}, 10 \mathrm{mg} / \mathrm{ml}$ aprotinin, $1 \mathrm{mg} / \mathrm{ml}$ leupeptin and $1 \mathrm{mM}$ orthovanadate for $30 \mathrm{~min}$ on ice and briefly sonicated. Immunoprecipitation was carried out by incubating the lysates with eNOS monoclonal antibody (1:1,000; catalog no. 32027S; Cell Signaling Technology, Inc.) ( $2 \mathrm{mg} / \mathrm{mg}$ of total cell protein) for $16 \mathrm{~h}$ at $4{ }^{\circ} \mathrm{C}$, followed by a $2 \mathrm{~h}$ incubation period with 1:1 protein A:protein G-sepharose slurry. Following centrifugation at $4^{\circ} \mathrm{C}$ and $13,400 \mathrm{x}$ g for $15 \mathrm{~min}$, the immunoprecipitates were washed with lysis buffer, re-suspended in loading buffer, boiled for $5 \mathrm{~min}$, and subjected to SDS-PAGE on $10 \%$ polyacrylamide gels and transferred to a nitrocellulose membrane. The primary antibody used for immunoblotting was anti-phospho-eNOS (Ser1177, 1:1,000 Cell Signaling Technology, Inc.). The membrane was then washed and incubated with secondary antibodies conjugated to horseradish 
peroxidase (1:2,500; catalog no. 554021; BD Biosciences) and processed as above.

Measurement of no. HUVECs were grown to $\sim 80 \%$ confluence in six-well plates $\left(1 \times 10^{6}\right.$ cells per well) and exposed to hypoxia for $30 \mathrm{~min}$. Next, NO release was measured using nitrate/nitrite colorimetric assay kits (Cayman Chemical Co, Ann Arbor, MI, USA). Briefly, cell culture supernatants were incubated with nitrate reductase for $3 \mathrm{~h}$ to convert nitrates into nitrites. The total amount of $\mathrm{NO}$ was then determined using the Griess reagent (Beyotime Institute of Biotechnology). A standard curve of nitric oxide was determined using known concentrations of nitrates, and the sample NO concentrations were calculated using the standard curve. Each assay was conducted in duplicate, and the results are expressed as nitrite $\mathrm{nM} / \mathrm{mg}$ protein in the cells.

Statistical analysis. The cell viability, cell apoptosis ratio and nitrite concentration results are expressed as the mean \pm standard deviation. The statistical analysis was performed using one-way analysis of variance followed by the Tukey's post-hoc test. $\mathrm{P}<0.05$ was considered to indicate a statistically significant difference. Analyses were performed using the SPSS statistical software package (version, 20.0; IBM SPSS, Armonk, NY, USA).

\section{Results}

High temperature stimulates apoptosis of HUVECs. Exposure to high temperature at $42^{\circ} \mathrm{C}$ for various time periods $(0.5,1,2$ or $4 \mathrm{~h})$ resulted in a drastic time-dependent decrease in HUVEC viability. A significant decrease in HUVEC viability was first observed by $2 \mathrm{~h}$ compared with baseline determined via a CCK-8 assay (Fig. 1A). The apoptosis cell ratio for the HUVECs that were exposure to the high temperature $\left(42^{\circ} \mathrm{C}\right)$ increased significantly by $30 \mathrm{~min}$, and significant increases in the apoptosis ratio were also found at 2 and $4 \mathrm{~h}$ (Fig. 1B). Caspase-3, the most important effector caspase for both extrinsic and intrinsic apoptosis pathways and engages subsequent activation of caspase-3, was detected, including its cleavage in heat-treated HUVECs. Cleaved caspase-3 accumulated in a time-dependent manner (Fig. 1C). The results above suggested that high temperatures suppress HUVEC viability and exert an apoptosis-inducing effect on HUVECs. Treatment with STS $(2 \mu \mathrm{g} / \mathrm{ml})$ significantly suppressed apoptosis of the HUVECs that were exposed to high temperature $\left(42^{\circ} \mathrm{C}\right.$; Fig. 1D). This result suggests that STS is a potential suppressor of heat stress-induced apoptosis.

STS inhibits heat stress-induced apoptosis of HUVECs by upregulating phosphorylated eNOS. NO is a crucial factor in vascular homeostasis and is endogenously produced by the terminal guanidino nitrogen of L-arginine of eNOS. To explore the mechanism of the effect of STS on heat stress-induced apoptosis of HUVECs, NO production was assessed via the production of nitrite. HUVECs were exposed to a high temperature at $42^{\circ} \mathrm{C}$ with or without treatment of STS $(2 \mu \mathrm{g} / \mathrm{ml})$ for various time periods $(15,30 \mathrm{~min}, 1$ or $2 \mathrm{~h}$ ). Without treatment with STS, nitrite production in the HUVECs under heat stress significantly increased at $0.5 \mathrm{~h}$ and decreased sharply at 1 and $2 \mathrm{~h}$, and nitrite production was under the baseline level at $2 \mathrm{~h}$ (Fig. 2A). However, for treatment with STS, the production of nitrite progressively increased and reached steady state at $1 \mathrm{~h}$, which was higher than the level of nitrite for no STS treatment (Fig. 2A). Because eNOS phosphorylation is a key event of NO production, the authors next determined the change in eNOS phosphorylation due to STS treatment in HUVECs exposed to heat stress. The time course of eNOS phosphorylation in high temperature-exposed cells was determined by immunoprecipitating with eNOS antibody and immunoblotting with phosphorylated eNOS at Ser 1177. Exposure to a high temperature at $42^{\circ} \mathrm{C}$ for various time periods $(15,30 \mathrm{~min} 1$ and $2 \mathrm{~h}$ ) resulted in increased eNOS phosphorylation at 15 and $30 \mathrm{~min}$ and sharp decreases in eNOS phosphorylation at 1 and $2 \mathrm{~h}$ compared with baseline (Fig. 2B). However, treatment with $5 \mu \mathrm{g} / \mathrm{ml} \mathrm{STS}$ resulted in a continual increase in eNOS phosphorylation from $15 \mathrm{~min}$ to $1 \mathrm{~h}$, which was sustained at $2 \mathrm{~h}$ (Fig. 2B). To confirm whether the STS-induced NO production increase and eNOS phosphorylation were associated with apoptosis suppression, the eNOS inhibitor L-NMMA was applied. HUVECs were pretreated with $30 \mu \mathrm{M} \mathrm{L}-\mathrm{NMMA}$ for $30 \mathrm{~min}$ followed by exposure to a temperature of $42^{\circ} \mathrm{C}$ with or without $2 \mu \mathrm{g} / \mathrm{ml} \mathrm{STS}$ treatment for $1 \mathrm{~h}$. Pretreatment with L-NMMA resulted in suppressed nitrite production even after treatment with STS (Fig. 2C). In addition, pre-treatment with L-NMMA stimulated apoptosis, which was triggered by the high temperature even in the presence of STS (Fig. 2D) and also resulted an increase in caspase-3 cleavage (Fig. 2E). These results suggested that STS suppressed HUVEC apoptosis that is otherwise induced by exposure to high temperatures via a mechanism that promotes NO production by increasing the phosphorylation of eNOS at Ser 1177.

STS promotes phosphorylation of eNOS in heat-treated HUVECs via the PI3K/AKT pathway. Following this, the authors examined the time course of AKT phosphorylation in high temperature-exposed HUVECs with or without STS treatment by immunoblotting cell lysates with an antibody directed against phosphorylated AKT at Ser 473. HUVECs were exposed to a high temperature of $42^{\circ} \mathrm{C}$ for various time periods $(15,30 \mathrm{~min}, 1$ or $2 \mathrm{~h})$ with or without $2 \mu \mathrm{g} / \mathrm{ml} \mathrm{STS}$ treatment. Without STS treatment, phosphorylated AKT levels at $15 \mathrm{~min}$ and $30 \mathrm{~min}$ were higher compared to baseline and lower at 1 and $2 \mathrm{~h}$ compared to baseline. However, STS treatment resulted in a continual increase in AKT phosphorylation in a time-dependent manner. It appeared that AKT phosphorylation stabilized by $1 \mathrm{~h}$ (Fig. 3A). The AKT inhibitor MK-2206 was applied to confirm whether eNOS phosphorylation was regulated by AKT phosphorylation. HUVECs were exposed to a temperature of $42^{\circ} \mathrm{C}$ for $1 \mathrm{~h}$ with or without $2 \mu \mathrm{g} / \mathrm{ml} \mathrm{STS}$ after pretreatment with $5 \mu \mathrm{M}$ MK-2206. eNOS phosphorylation levels were determined by immunoprecipitating with the eNOS antibody and immunoblotting with phosphorylated eNOS at Ser 1177. Pretreatment with MK-2206 suppressed the increase in eNOS phosphorylation induced by STS treatment in the high temperature-exposed HUVECs (Fig. 3B). The nitrite product was also determined. Pretreatment with MK-2206 significantly suppressed the STS-induced increase in nitrite production in 
A

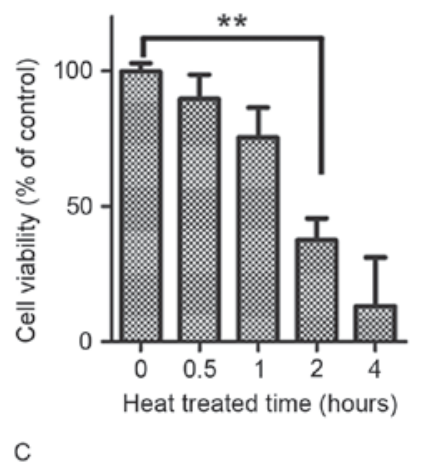

B
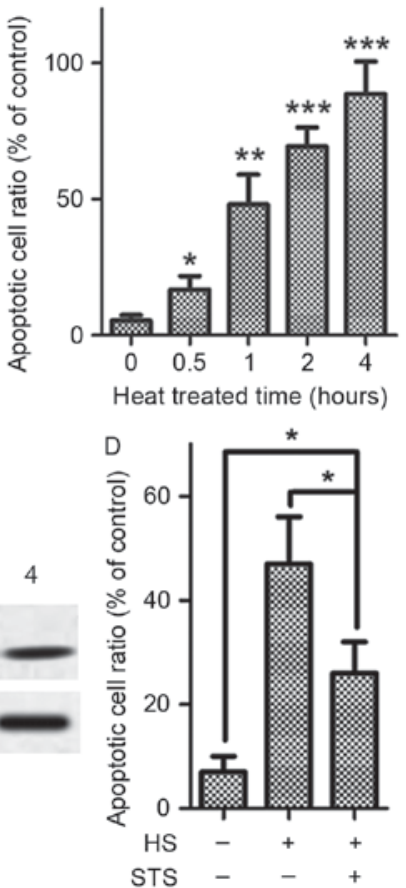

Figure 1. Heat treatment triggered apoptosis of HUVECs. HUVECs were exposed to $42^{\circ} \mathrm{C}$ for the time duration. (A) CKK-8 assays were applied to determine cell viability. (B) Apoptosis was examined via flow cytometry following Annexin V and PI staining. (C) Total HUVEC proteins were used for western blot analysis with antibodies against caspase- 3 and actin. (D) HUVECs were exposed to $42^{\circ} \mathrm{C}$ for $1 \mathrm{~h}$, and apoptosis was examined as described in (B); the cells were treated with $2 \mu \mathrm{g} / \mathrm{ml}$ STS 30 min prior to heat exposure. ${ }^{*} \mathrm{P}<0.05,{ }^{* * *} \mathrm{P}<0.01$, as indicated in A and $\mathrm{D} ;{ }^{*} \mathrm{P}<0.05,{ }^{* *} \mathrm{P}<0.01,{ }^{* * *} \mathrm{P}<0.001$ vs. control in B. HUVECs, human umbilical vein endothelial cells.

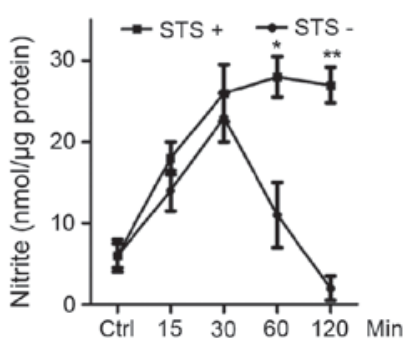

C

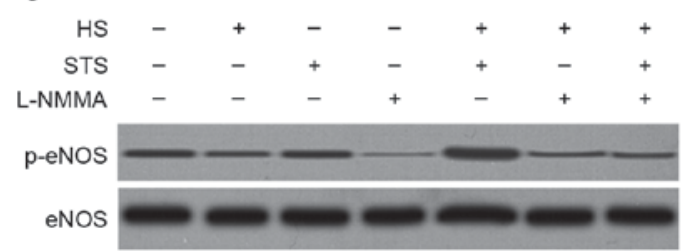

$\mathrm{E}$

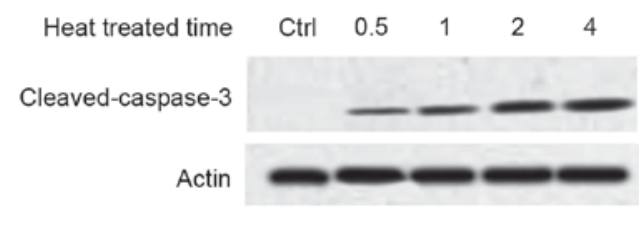

B

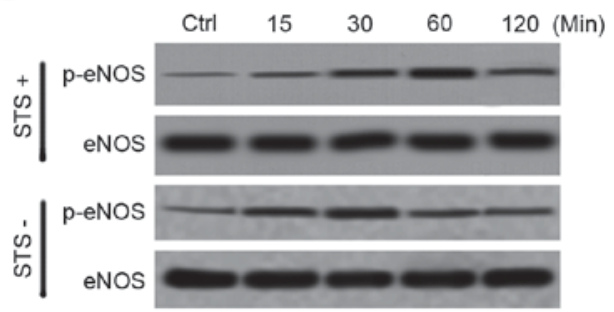

D

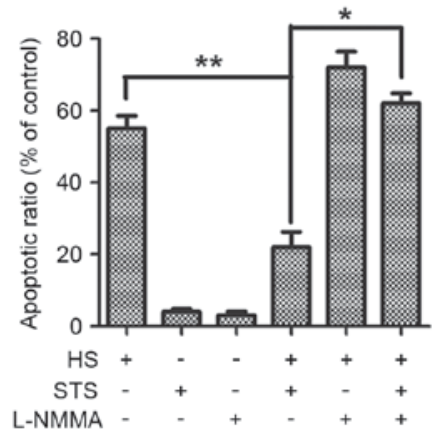

Cleaved caspase-3

Actin

Figure 2. STS inhibited heat stroke-induced apoptosis of HUVECs by upregulating phosphorylation of eNOS. HUVECs were exposed to $42^{\circ} \mathrm{C}$ for the indicated time duration with or without $2 \mu \mathrm{g} / \mathrm{ml} \mathrm{STS}$ treatment. (A) Nitrite in whole-cell lysates was determined using nitrite kits. (B) Whole-cell lysates were immunoprecipitated with an eNOS antibody and immunoblotted with phosphorylated eNOS (at Ser 1177). HUVECs were exposed to $42^{\circ} \mathrm{C}$ for $1 \mathrm{~h}$ with or without $30 \mu \mathrm{M}$ L-NMMA pre-treatment for $30 \mathrm{~min}$ and with or without $2 \mu \mathrm{g} / \mathrm{ml} \mathrm{STS}$ treatment, which was added 30 min before HS. (C) Whole cell lysates were collected and analyzed as described in (B). (D) Apoptosis was examined via flow cytometry following Annexin V and PI staining. (E) The total proteins of the HUVECs were used for western blot analysis with antibodies against caspase-3 and actin. ${ }^{*} \mathrm{P}<0.05,{ }^{* *} \mathrm{P}<0.01$ as indicated. STS, sodium tanshinone IIA sulfonate; HUVECs, human umbilical vein endothelial cells; eNOS, endothelial nitric oxide synthase; HS, heat shock. 
A

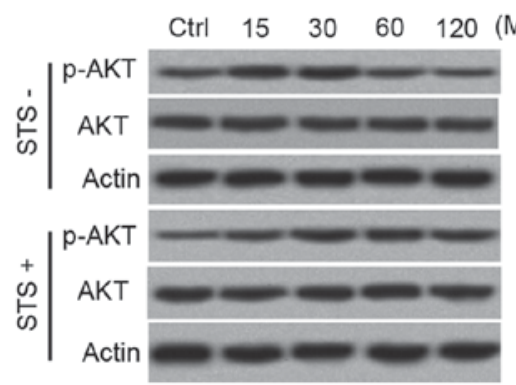

C

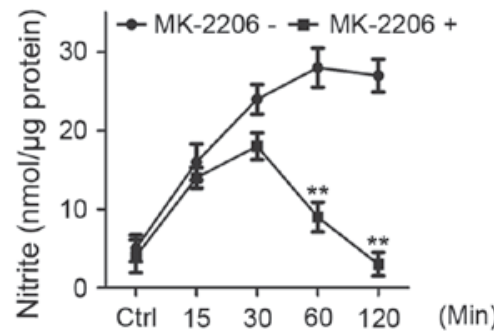

E

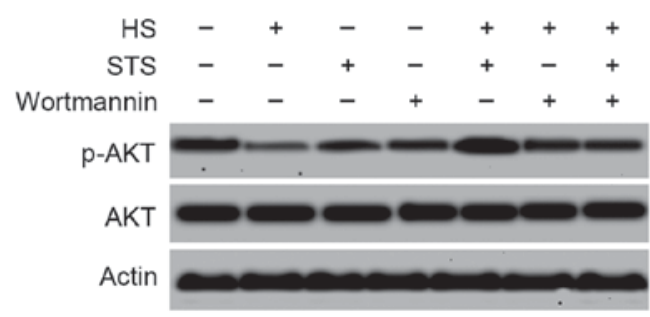

B

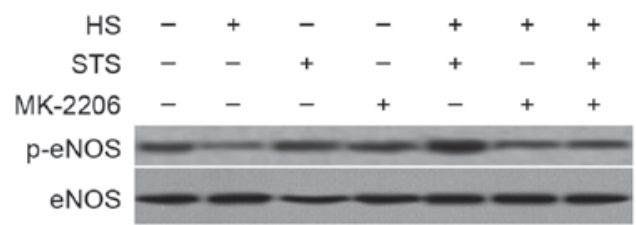

D

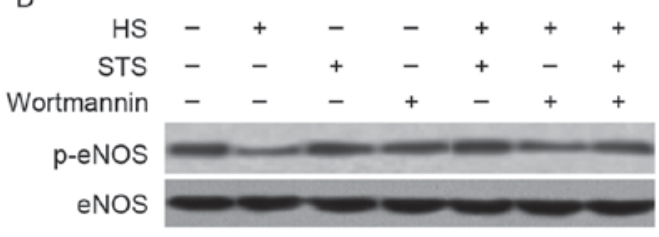

$\mathrm{F}$

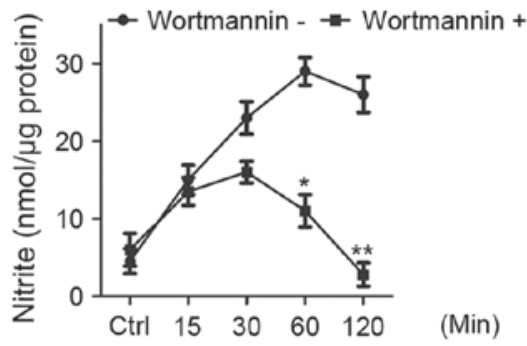

Figure 3. STS activated the PI3K/AKT pathway to promote nitric oxide production in HUVECs under heat stress. HUVECs were exposed to $42^{\circ} \mathrm{C}$ for various time periods $(15,30 \mathrm{~min}, 1$ or $2 \mathrm{~h}$ ) with or without $2 \mu \mathrm{g} / \mathrm{ml}$ STS treatment. (A) The total HUVEC proteins of were used for western blot analysis with antibodies against AKT, phosphorylated AKT (at Ser 473) and $\beta$-actin. HUVECs were exposed to $42^{\circ} \mathrm{C}$ for $1 \mathrm{~h}$ with or without $5 \mu \mathrm{M} \mathrm{MK-2206}$ pre-treatment for 30 min and with or without treatment with $2 \mu \mathrm{g} / \mathrm{ml}$ STS, which was added $30 \mathrm{~min}$ in advance. (B) Whole-cell lysates were immunoprecipitated with an eNOS antibody and immunoblotted with phosphorylated eNOS (at Ser 1177). (C) The HUVECs were exposed to $42^{\circ} \mathrm{C}$ for $1 \mathrm{~h}$ and STS was added 30 min in advance with or without pre-treatment with $5 \mu \mathrm{M}$ MK-2206 for $30 \mathrm{~min}$. Nitrite in whole cell lysates were determined using nitrite kits for the different time periods, as indicated $(15,30 \mathrm{~min}, 1$ or $2 \mathrm{~h}) .{ }^{*} \mathrm{P}<0.05,{ }^{* *} \mathrm{P}<0.01$ vs. controls. HUVECs were exposed to $42^{\circ} \mathrm{C}$ for $1 \mathrm{~h}$ with or without $500 \mathrm{nM}$ wortmannin pre-treatment for $30 \mathrm{~min}$ and with or without $2 \mu \mathrm{g} / \mathrm{ml}$ STS treatment, which was added $30 \mathrm{~min}$ in advance. (D) Whole-cell lysates were collected and analyzed as described in (B). (E) Whole cell lysates were collected and analyzed as described in (A). (F) The HUVECs were exposed to $42^{\circ} \mathrm{C}$ for $1 \mathrm{~h}$, and STS was added 30 min in advance with or without $500 \mathrm{nM}$ wortmannin pre-treatment for $30 \mathrm{~min}$. Nitrite in whole cell lysates were determined using nitrite kits for different time periods, as indicated (15, 30 min, 1 , or 2 h). " $\mathrm{P}<0.05,{ }^{*}$ P $<0.01$ vs. controls. STS, sodium tanshinone IIA sulfonate; PI3K, phosphatidylinositol-3 kinase; AKT, protein kinase B; HUVECs, human umbilical vein endothelial cells; eNOS, endothelial nitric oxide synthase.

the high temperature-exposed HUVECs (Fig. 3C). The results suggest that STS upregulates eNOS phosphorylation via AKT activation. Because both eNOS and AKT are downstream targets of PI3K, whether STS-induced phosphorylation of eNOS and Akt are regulated by a PI3Kinase-dependent mechanism was investigated. HUVECs were exposed to a high temperature of $42^{\circ} \mathrm{C}$ with or without $2 \mu \mathrm{g} / \mathrm{ml} \mathrm{STS}$ treatment following pretreatment with the PI3K inhibitor wortmannin (500 nM). eNOS phosphorylation at Ser 1177 and AKT phosphorylation at Ser 473 were detected, as above. Treatment with wortmannin suppressed the increases in eNOS and AKT phosphorylation that is induced by STS in high temperature-exposed HUVECs (Fig. 3D and E). In addition, treatment with wortmannin suppressed the increased nitrite levels that are induced by STS in high temperature-exposed HUVECs (Fig. 3F). The results suggested that PI3K promotes AKT and eNOS phosphorylation, thus stimulating NO production in high temperature-exposed HUVECs.
STS suppressed heat stress-stimulated apoptosis involving PI3K/AKT/eNOS pathway activation. The effects of treatment with the eNOS phosphorylation inhibitor L-NMMA, the AKT phosphorylation inhibitor MK-2206, or the PI3K inhibitor wortmannin on heat stress-stimulated apoptosis were observed to test whether the PI3K/AKT/eNOS pathway serves a critical role in the apoptosis-suppressing function of STS. Following pretreatment with or without MK-2206 or wortmannin, HUVECs were exposed to a high temperature of $42^{\circ} \mathrm{C}$ with or without treatment with $2 \mu \mathrm{g} / \mathrm{ml} \mathrm{STS}$, and apoptosis cell ratios were examined via flow cytometry. Under the heat stress condition, pretreatment with MK-2206 resulted in an increase in the apoptosis cell ratio regardless of STS treatment (Fig. 4A). The same phenomenon occurred due to pretreatment with wortmannin (Fig. 4B). Whole-cell lysates were used to analyze the cleavage of casepase-3. Pretreatment with MK-2206 resulted in an increase in cleaved casepase-3 regardless of the existence of STS (Fig. 4C). Pretreatment with 
A

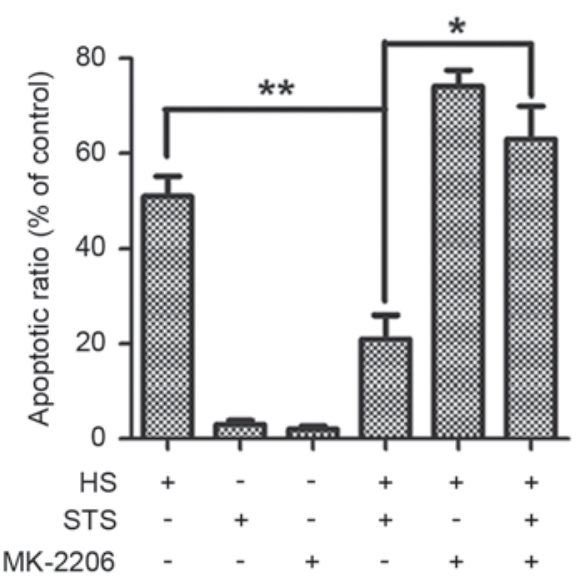

B

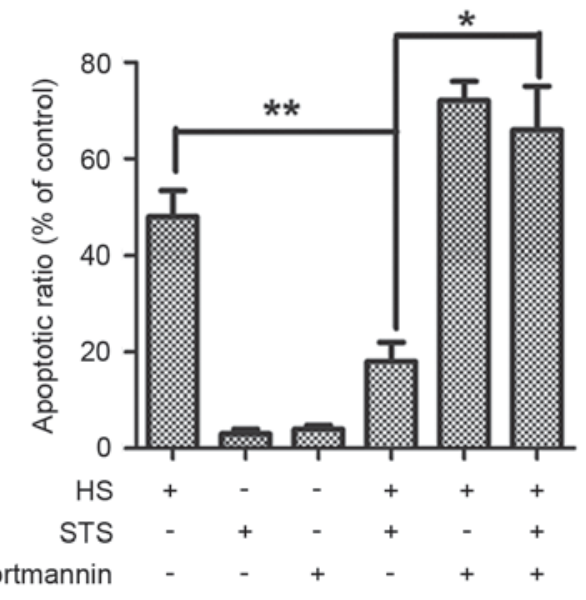

C

$\begin{array}{rccccccc}\text { HS } & - & + & - & - & + & + & + \\ \text { STS } & - & - & + & - & + & - & + \\ \text { MK-2206 } & - & - & - & + & - & + & +\end{array}$

Cleaved caspase-3

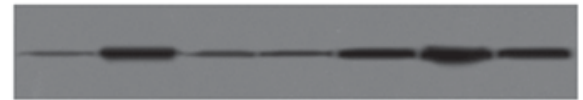

Actin

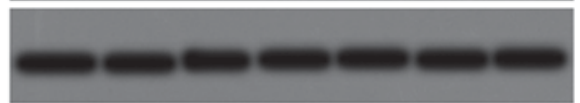

D

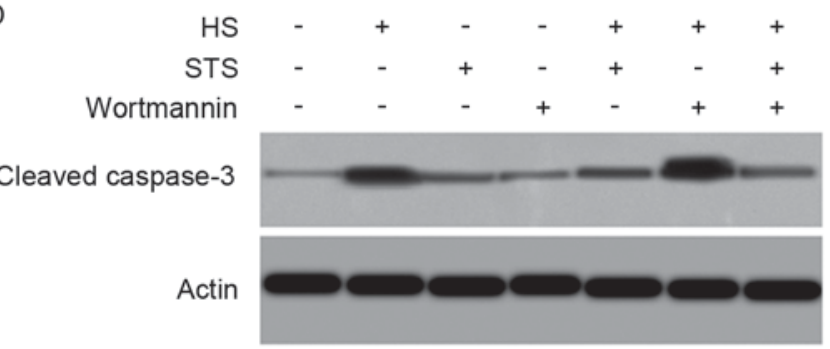

Figure 4. Heat stress-induced apoptosis was suppressed by STS through the PI3K/AKT pathway. HUVECs were exposed to $42^{\circ} \mathrm{C}$ for $1 \mathrm{~h}$ with or without of $5 \mu \mathrm{M}$ MK-2206 pre-treatment or $500 \mathrm{nM}$ wortmannin pre-treatment for $30 \mathrm{~min}$ and with or without $2 \mu \mathrm{g} / \mathrm{ml} \mathrm{STS}$ treatment, which was added 30 min before heat exposure. (A and B) Apoptosis was examined via flow cytometry following Annexin V and PI staining. (C and D) The total HUVEC proteins were used for western blot analysis with antibodies against caspase- 3 and $\beta$-actin. ${ }^{*} \mathrm{P}<0.05,{ }^{* *} \mathrm{P}<0.01$ as indicated. STS, sodium tanshinone IIA sulfonate; PI3K, phosphatidylinositol-3 kinase; AKT, protein kinase B; HUVECs, human umbilical vein endothelial cells; HS, heat shock.

wortmannin produced the same results (Fig. 4D). These results suggested that STS suppresses the heat-induced apoptosis of HUVECs though the PI3K/AKT pathway. The data presented in Fig. 2D and E demonstrate that the reduction in heat-induced apoptosis also involved eNOS phosphorylation at Ser 1177. STS-induced eNOS phosphorylation was regulated by PI3K/AKT, as presented in Fig. 3. Therefore, the authors believe that STS suppressed heat stress-induced apoptosis by stimulating the PI3K/AKT/eNOS pathway, which was also critical for the increase in STS-induced NO production.

\section{Discussion}

The present study of the effects of high temperature on HUVECs demonstrated that heat stress stimulated a reduction in cell viability and enhancements in caspase-3 cleavage and apoptosis in a time-dependent manner. In addition, heat stress induced eNOS phosphorylation at Ser 1155 in as early as $15 \mathrm{~min}$, peaking at $30 \mathrm{~min}$, and then sharply decreasing after $1 \mathrm{~h}$. However, STS treatment significantly suppressed the heat stress-induced apoptosis, maintaining elevated eNOS phosphorylation for up to $2 \mathrm{~h}$, and led to an increase in NO production. The STS-induced increase in NO production was ablated by pretreatment with the eNOS inhibitor, L-NMMA. The present studies also revealed that STS treatment induces a significant increase in AKT phosphorylation. Further, inhibition of AKT activation induced significant elevations in STS-induced eNOS phosphorylation and NO production. Additionally, inhibition of the PI3Kinase resulted in significant suppression of the STS-induced increases in AKT phosphorylation, eNOS phosphorylation and NO production. In addition, these data demonstrated that inhibition of the $\mathrm{PI} 3 \mathrm{~K} / \mathrm{AKT}$ pathway suppressed the increase in STS-induced NO production.

The present data suggested that heat stress suppresses the physiological viability of endothelial cells, promoting apoptosis and inhibiting the synthesis and release of vasoactive substances. STS is a potential inhibitor of heat stress-induced apoptosis, and NO is considered an important mediator of the effect. A previously published study on endothelial cells 
have demonstrated that NO production is regulated by eNOS activity (18). NOS phosphorylation at Ser 1177 has been widely considered an important mechanism for increasing NO production under various stimuli, including shear stress. The current study of HUVECs under heat stress demonstrated that high temperatures stimulate phosphorylation of eNOS at Ser 1177 , increasing NO production at an early stage. However, the mechanism does not apply to long-term exposure to high temperatures. However, STS treatment promotes eNOS phosphorylation at Ser1177 and increases NO production in a sustained manner in HUVECs, even under heat stress conditions. Furthermore, the present study suggests that inhibition of eNOS results in suppression of the STS-induced increase in NO production. Furthermore, the study revealed that inhibition of eNOS, either by a PI3K inhibitor or an AKT phosphorylation inhibitor, significantly attenuates STS-induced eNOS activity and NO production. Therefore, eNOS phosphorylation at Ser 1177 is likely required for STS-induced eNOS activation and NO production in HUVECs under heat stress conditions.

AKT, also known as protein kinase B, is an important oncogene involved in cell survival. AKT is phosphorylated by tyrosine kinase G-coupled receptors under shear stress, ultimately downregulating signals (19). The PI3K/AKT/eNOS phosphorylation signal pathway has been reported to serve a significant role in NO production. Blocking of the PI3K/AKT pathway leads to reduced NO release in human endothelial cells. In addition, eNOS phosphorylation caused by shear stress in cultured endothelial cells has been reported to be related to PI3K/AKT signaling (19). Furthermore, overexpression of a constitutively active $\mathrm{AKT}_{\mathrm{Myr}}$ mutant increased eNOS phosphorylation and NO production (20). The present study demonstrated that STS treatment markedly increases AKT phosphorylation, and a blockade of PI3K/AKT suppresses STS-induced eNOS phosphorylation, which indicates that the PI3K/AKT pathway regulates STS-induced eNOS phosphorylation.

STS is a derivative of tanshinone II A and is used for the treatment of diabetic nephropathy, acting as an anti-inflammatory and anti-fiber agent. Some studies have revealed that STS suppress inflammatory responses $(21,22)$. Our previous study demonstrated that STS has potential in systematic inflammation inhibition. The present study suggests that STS prevents heat stress-induced endothelium injury. This may be the mechanism responsible for STS-induced systematic anti-inflammation.

\section{References}

1. Bouchama A and Knochel JP: Heat stroke. N Engl J Med 346 1978-1988, 2002.

2. Geng Y, Ma Q, Liu YN, Peng N, Yuan FF, Li XG, Li M, Wu YS, Li BL, Song WB, et al: Heatstroke induces liver injury via IL-1 $\beta$ and HMGB1-induced pyroptosis. J Hepatol 63: 622-633, 2015.
3. Tang J, Deng P, Jiang Y, Tang Y, Chen B, Su L and Liu Z: Role of HMGB1 in propofol protection of rat intestinal epithelial cells injured by heat shock. Cell Biol Int 37: 262-266, 2013.

4. Leon LR and Bouchama A: Heat stroke. Compr Physiol 5: 611-647, 2015.

5. Epstein Y, Roberts WO, Golan R, Heled Y, Sorkine P and Halpern P: Sepsis, septic shock, and fatal exertional heat stroke. Curr Sports Med Rep 14: 64-69, 2015.

6. Iba T, Gando S, Murata A, Kushimoto S, Saitoh D, Eguchi Y, Ohtomo Y, Okamoto K, Koseki K, Mayumi T, et al: Predicting the severity of systemic inflammatory response syndrome (SIRS)-associated coagulopathy with hemostatic molecular markers and vascular endothelial injury markers. J Trauma 63: 1093-1098, 2007.

7. Gando S: Systemic inflammatory response syndrome (SIRS) and endothelial cell injury. Nihon Rinsho 62: 2244-2250, 2004 (In Japanese).

8. Sylman JL, Artzer DT, Rana K and Neeves KB: A vascular injury model using focal heat-induced activation of endothelial cells. Integr Biol (Camb) 7: 801-814, 2015.

9. Hawiger J, Veach RA and Zienkiewicz J: New paradigms in sepsis: From prevention to protection of failing microcirculation. J Thromb Haemost 13: 1743-1756, 2015.

10. Krau SD: Heat-related illness: A hot topic in critical care. Crit Care Nurs Clin North Am 25: 251-262, 2013.

11. Bruchim Y, Loeb E, Saragusty J and Aroch I: Pathological findings in dogs with fatal heatstroke. J Comp Pathol 140: 97-104, 2009.

12. Liu Y, Zhou G, Wang Z, Guo X, Xu Q, Huang Q and Su L: NF-кB signaling is essential for resistance to heat stress-induced early stage apoptosis in human umbilical vein endothelial cells. Sci Rep 5: 13547, 2015.

13. Li L, Tan H, Gu Z, Liu Z, Geng Y, Liu Y, Tong H, Tang Y, Qiu J and $\mathrm{Su} \mathrm{L}$ : Heat stress induces apoptosis through a $\mathrm{Ca}^{2+}$-mediated mitochondrial apoptotic pathway in human umbilical vein endothelial cells. PLoS One 9: e111083, 2014.

14. Kim YM, Bombeck CA and Billiar TR: Nitric oxide as a bifunctional regulator of apoptosis. Circ Res 84: 253-256, 1999.

15. Napoli C, Paolisso G, Casamassimi A, Al-Omran M, Barbieri M, Sommese L, Infante T and Ignarro LJ: Effects of nitric oxide on cell proliferation: Novel insights. J Am Coll Cardiol 62: 89-95, 2013.

16. Takahashi K, Ouyang X, Komatsu K, Nakamura N, Hattori M, Baba A and Azuma J: Sodium tanshinone IIA sulfonate derived from Danshen (Salvia miltiorrhiza) attenuates hypertrophy induced by angiotensin II in cultured neonatal rat cardiac cells. Biochem Pharmacol 64: 745-749, 2002.

17. Wang C, Li H, Zhou K, Luo C, Li Y, Xie L and Hua Y: Sodium tanshinone IIA sulfonate and sodium danshensu open the placental barrier through down-regulation of placental P-glycoprotein in mice: Implications in the transplacental digoxin treatment for fetal heart failure. Int J Cardiol 176: 1331-1333, 2014.

18. Cirino G, Fiorucci S and Sessa W C: Endothelial nitric oxide synthase: The Cinderella of inflammation? Trends Pharmacol Sci 24: 91-95, 2003.

19. Dimmeler S, Fleming I, Fisslthaler B, Hermann C, Busse R and Zeiher AM: Activation of nitric oxide synthase in endothelial cells by Akt-dependent phosphorylation. Nature 399: 601-605, 1999.

20. Gonzalez E, Kou R, Lin AJ, Golan DE and Michel T: Subcellular targeting and agonist-induced site-specific phosphorylation of endothelial nitric-oxide synthase. J Biol Chem 277: 39554-39560, 2002.

21. Zhang Y, Li W, Zhu S, Jundoria A, Li J, Yang H, Fan S, Wang P, Tracey KJ, Sama AE and Wang H: Tanshinone IIA sodium sulfonate facilitates endocytic HMGB1 uptake. Biochem Pharmacol 84: 1492-1500, 2012.

22. Hu Q, Wei B, Wei L, Hua K, Yu X, Li H and Ji H: Sodium tanshinone IIA sulfonate ameliorates ischemia-induced myocardial inflammation and lipid accumulation in Beagle dogs through NLRP3 inflammasome. Int J Cardiol 196: 183-192, 2015. 